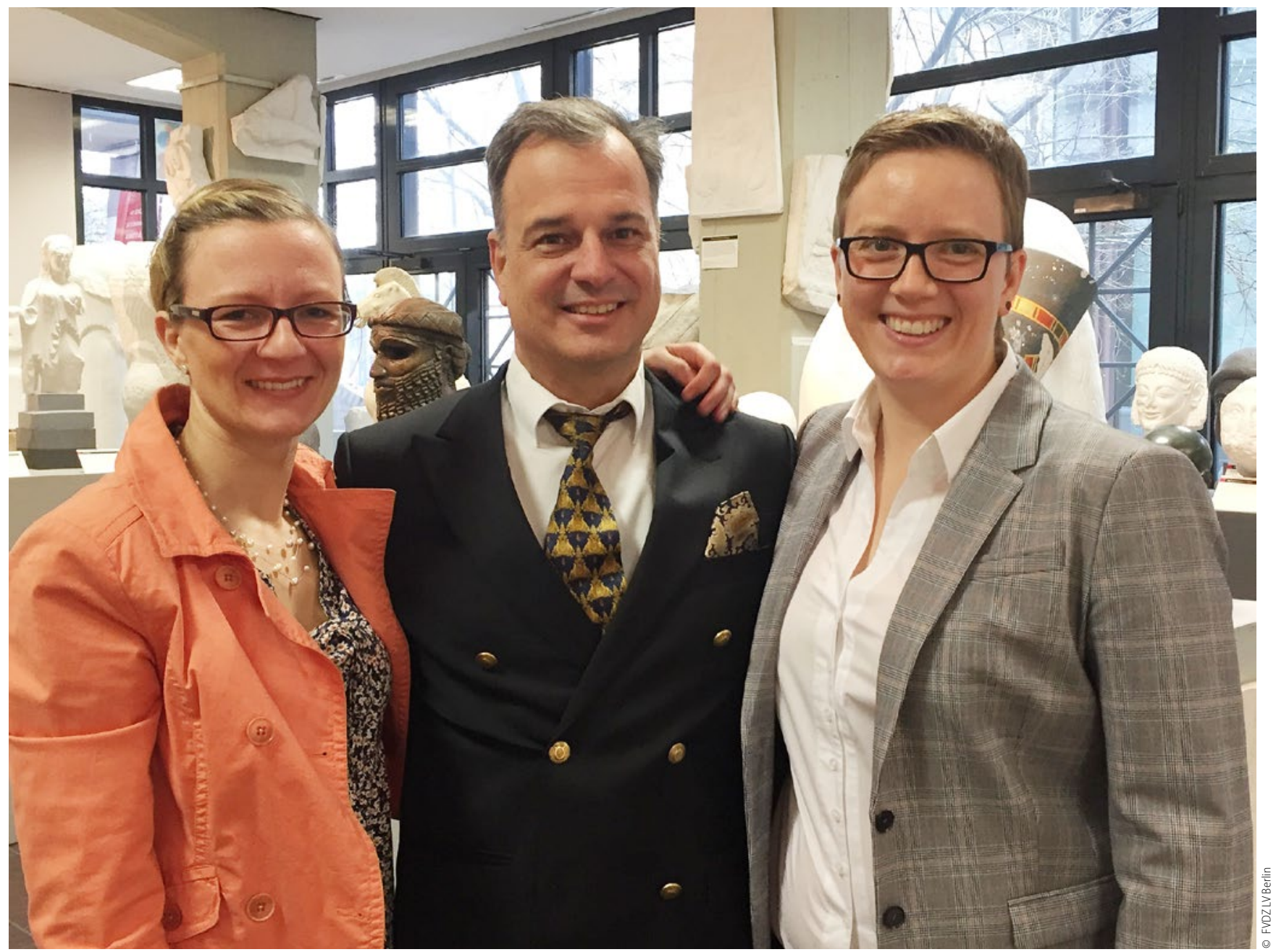

Die FVDZ-Mitglieder des Berliner Kammervorstandes Juliane von Hoyningen-Huene, Dr. Michael Dreyer und Dr. Jana Lo Scalzo (v.li.).

Delegierte und Vorstandsmitglieder

\title{
Freier Verband in Berliner KZV und Kammer stark vertreten
}

In Berlin fanden 2016 die Wahlen zur Vollversammlung der Kassenzahnärztlichen Vereinigung (KZV) und zur Delegiertenversammlung der Zahnärztekammer statt. Der FVDZ-Landesverband Berlin stellt in beiden Gremien Delegierte und auch Vorstandsmitglieder.

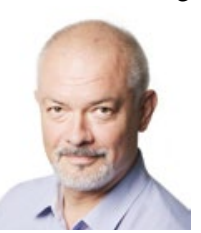

Die Vertreterversammlung der KZV wählte Mitte Januar 2017 in ihrer konstituierenden Sitzung erneut Karsten Geist zum stellvertretenden Vorsitzenden in den dreiköpfigen Vorstand. Damit kann er seine erfolgreiche Arbeit für eine Legislaturperiode von sechs Jahren fortsetzen. Für die KZV stellt der FVDZ sechs Vertreter.

Anfang Februar fand die konstituierende Delegiertenversammlung der Zahnärztekammer Berlin statt. Die insgesamt neun Delegierten des Freien Verbandes konnten drei ihrer Mitglieder in den Vorstand wählen. Weiterhin können Dr. Michael Dreyer und Juliane von Hoyningen-Huene ihre Posten als Vizepräsident und Leiterin des Referates für zahnärztliche Fort- und Weiterbildung besetzen. Als neues Mitglied im Vorstand steht Dr. Jana Lo Scalzo dem GOZ-Referat vor.

FVDZ-Landesverband Berlin

\footnotetext{
Save the dates!

Die diesjährige Klausurtagung des FVDZ-Landesverbandes Berlin ist vom 16. bis 17. Juni. Der Termin für die Landesversammlung wurde auf den 15. September festgelegt. Genauere Informationen zu beiden Veranstaltungen folgen in Kürze.
} 